\title{
Safer Frother Option for Coal Flotation - A Review
}

\author{
Akira Otsuki $^{{ }^{*}}$, Tamara Miller ${ }^{2}$ \\ ${ }^{1}$ Ecole Nationale Supérieure de Géologie, GeoRessources UMR 7359 CNRS, University of Lorraine, \\ 2 Rue du Doyen Marcel Roubault, BP 10162, 54505 Vandoeuvre-lès-Nancy, France. \\ ${ }^{2}$ WA School of Mines, Curtin University, Kalgoorlie, Australia \\ Email: akira.otsuki@univ-lorraine.fr
}

\begin{abstract}
A safer frother option for coal flotation in comparison with the common frother methyl isobutyl carbinol (MIBC) was searched and compared through literature review. Results of literature review and comparison of different frothers in safety and environmental aspects show that pine oil and DowFroth have a strong potential to replace MIBC since it has high flash point $\left(78{ }^{\circ} \mathrm{C}, 149{ }^{\circ} \mathrm{C}\right.$, respectively), and dual frothing and collecting properties to be used as a stand-alone reagent for coal flotation. It can significantly reduce the risk of potential hazard associated with MIBC and oil collector.
\end{abstract}

Keywords: Occupational health and safety, flash point, exposure, environment, methyl isobutyl carbinol.

\section{Introduction}

Occupational health and safety (OHS) is set to create a safe working environment to employees. In Australia, for example, each state government places a different set of mining regulations. These regulations are continuously getting stricter on items allowed in mine sites. Many metallurgical processes require the use of hazardous chemicals which could create hazards while in transport, use and disposal. Since the regulations are getting stricter, some of those chemicals may not be allowed to be used in mine sites in the future. This creates the need to find safer alternative chemicals or processes to keep employees safe. Coal processing is one of such processes that use hazardous reagents. Methyl isobutyl carbinol (MIBC, $\mathrm{C}_{6} \mathrm{H}_{14} \mathrm{O}$ ) is a common frother but also collector used in coal flotation and has a low flash point $\left(\right.$ F.P. $\left.=39{ }^{\circ} \mathrm{C} ;[1]\right)$. This can cause incidents such as what happened in a Queensland coal preparation plant in 2003. The power to some MIBC pumps was tripped, once they were reset, powered up a flash and then a fire was observed behind the pumps. This is due to the flash point of MIBC being $39{ }^{\circ} \mathrm{C}$ and as the vapour is heavier than air, an explosive mix will form under the right conditions [2]. There have also been incidents involving MIBC transport trucks. These dangers highlight the need to find a safer frother reagent. Thus, frother manufacturers are trying to develop/find alternatives.

Coal has been used as an energy source for hundreds of years, and becoming more important in recent years. In 2011, it generated $42 \%$ of the world's electricity and was recorded as one of the fastest growing energy sources [3]. There are two major coal categories. Thermal coal is used mainly for power generation while metallurgical coal is used in raw iron manufacturing. Thermal coal has a relatively low value, meaning that less cost intensive processes have to apply for its recovery. Metallurgical coal used in the manufacture of metallurgical coke is, on the other hand, worth more; so companies can use more cost extensive process methods for its recovery. Coal can be mined from either surface or underground. In Australia, as an example, the major source is surface-mining, which affects the coal processing and also its use as an energy source. The closer to the surface the coal recovered from, the more weathered and oxidized it becomes. The oxidized coal exhibits different properties from the underground coal with its unoxidized surface. Such oxidation can make coal difficult to process by flotation because oxidized coal surface is less hydrophobic. Therefore, the intense coal oxidation requires modifications of extraction methodology.

Once the coal is mined, it can be classified into four size categories: coarse particles $(+10 \mathrm{~mm})$, intermediate $(10 \mathrm{~mm}-1 \mathrm{~mm})$, fine $(1 \mathrm{~mm}-150 \mu \mathrm{m})$ and ultrafine $(-150 \mu \mathrm{m})$ particles [4]. To separate 
coal from gangue minerals, gravity separation is applied for coarse and intermediate particles while froth flotation is used for the fine and ultrafine particles.

In this study, a number of different frothers are compared in terms of safety and environmental concerns as well as coal flotation performance. This study aims to discuss and find safer alternatives for coal flotation frother that does not pose any significant OH\&S hazards but still achieve similar or better flotation performance, in comparison with MIBC, currently the most common frother for coal flotation around the world. That is because its Safety Data Sheet (SDS) alerts its moderate risk due to its low flash point [1] and there have been some fire incidents in mine site [e.g. 2]. For these reasons, an alternative reagent without such a risk would be beneficial for the coal mining industry.

This study would be beneficial for the coal industry to improve their safety and environmental standards. In addition, if the oxidized coal can be floated successfully without the use of MIBC and/or other reagents that can cause hazards, it can assist in a safer mining operation for employees. Processing oxidized or low rank coal deposits economically viable using flotation and improving recovery can make significant profit for coal industry.

\section{Froth Flotation}

Froth flotation uses the difference in hydrophobicity of mineral surfaces to separate valuable minerals from gangue minerals using air bubbles. Hydrophobic particles are attached onto bubbles rising and forming a froth layer at the air-water interface. The hydrophilic particles, on the other hand, remain in the slurry due to small attraction with bubbles. Various reagents are added to alter the properties of minerals and bubbles. One of them is frother, which is responsible for the generation of a stable froth layer with nucleation of small stable bubbles [5]. The froth is made of air bubbles, solids and water. When bubbles come into contact, the liquid film between them thins and breaks, making the bubbles coalesce [6]. With the addition of frothers, the rate of coalescence is reduced, and creating a more stable froth.

The principle role of frother is the creation of fine stable bubbles. A frother contains a polar group and a non-polar hydrocarbon radical. During the froth flotation process; the hydrophilic polar group is facing the water phase while the hydrocarbon faces towards the air phase [6]. This is the reason why some frothers also can act as a collector based on the non-selective adsorption onto not only air bubbles but also mineral particles whose surface can become hydrophobic. With small amount of frother addition, it can improve oxidized coal flotation. The frother adsorbs onto the coal - water interface and provides the collector an anchor point [7]. In other words, a frother might work as an activator. However, once the frother addition exceeded a certain concentration, the frothers started to adsorb on to the coal surface, leading it to more hydrophilic. In other words, the frother can largely coat the bubble and the coal surface creating a repulsive force between them and reduce the coal flotation recovery [8].

When a frother is used as an emulsifier, it helps dispersion of oil collector (e.g. diesel oil) into fine droplets. These finer droplets of oil increase the probability of coal particle - oil droplet collisions thus improving the flotation kinetics [8]. The oily collector must also be able to spread over the coal surface. When the coal surface is oxidized, generated surface functional groups interact with water molecules making the surface hydrophilic. The rate that the collector molecules adsorbed onto particles is determined by the contact angle and the oil-water interfacial tension. The oil droplets displace the water from the coal surface if the oil - water interfacial tension is decreased. This tension is reduced by the frother addition, which ultimately increases the hydrophobicity of the coal surface [9]. There appears to be two ways in which the frothers adsorb onto the coal surface. The first and the strongest interaction is the hydrogen bonding between the functional groups on the coal surface and the polar end of a frother molecule. The second involves the non-polar end of the frother molecule interacting with the carbonaceous sites on the coal surface through the van der Waal forces [9].

The most common frother group for coal flotation is the aliphatic alcohols (ROH) which include MIBC [10]. They have a carbon chain length of five to eight and a single hydroxide group with a limited solubility in water, except diacetone alcohol $\left(\mathrm{C}_{6} \mathrm{H}_{12} \mathrm{O}_{2}\right.$; moderate solubility). Cyclic alcohols include pine and eucalyptus oils, and have both frothing and collecting properties. Polyglycol-type frothers are derived from ethylene or propylene and ranged from partially soluble to completely miscible in water. 
The power and selectivity of the frothers is related to the molecular weight [11]. A frother with large molecular weight has a strong frothing property while the one with small molecular weight is more selective.

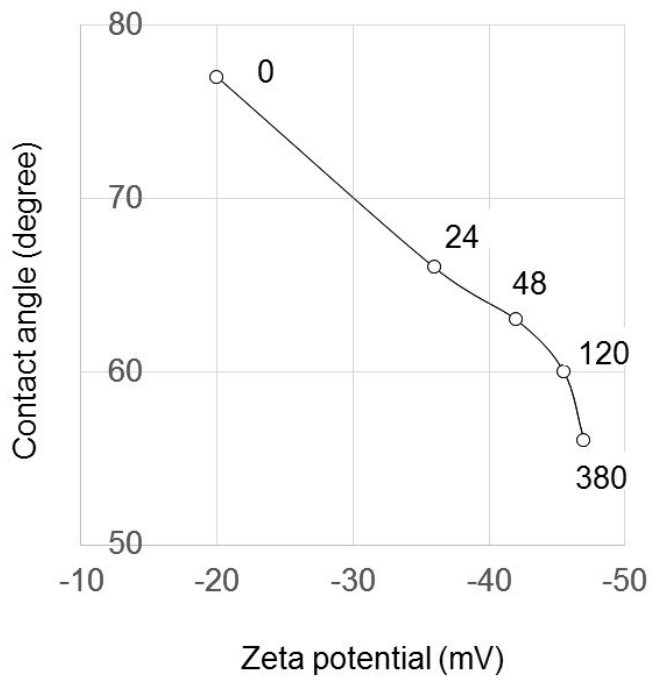

Figure 1. Contact angle and zeta potential of oxidized bituminous coal. Numbers next to the plots indicate the oxidation time (h) at $125^{\circ} \mathrm{C}$ (reproduced from [16])).

\section{Coal Flotation and Reagents}

Coal flotation performance depends mainly on the natural hydrophobicity/oxidation, size and rank of coal particles, and the properties of reagents used. Freshly mined coal has a higher hydrophobicity than weathered coals recovered from the mine surface or stockpiled for an extended period. Coal surface is naturally hydrophobic; but there are a range of chemicals used to further enhance the floatability of coal particles and thus the process efficiency. Hydrocarbon oils such as diesel oil and kerosene are often used as collectors since they work fine and are cost effective, in comparison with other commercial collector reagents. Methyl isobutyl carbinol (MIBC) and glycols are common frothers. There are a number of other modifiers and depressants that can be used in coal flotation to enhance an efficiency of coal extraction process; but they are out of discussion in this paper.

Using these reagents in flotation, however, can create unnecessary occupational health and safety $(\mathrm{OH} \& \mathrm{~S})$ hazards in coal mine sites. If OH\&S standards continue to tighten, reagents such as MIBC, which is currently nominated as a moderate risk, are not going to be allowed to be stored on site. Thus, there is a strong need to find alternative reagents that do not pose any safety or environmental threats.

Surface properties of coal particles affect most their froth flotation behaviour. Coal is naturally hydrophobic and repels water, while associated gangue minerals (e.g. silicates; [12]) tend to be hydrophilic. When a water drop is placed on a fresh coal surface, it remains as a droplet. The angle the water droplet and the surface form is called contact angle. The larger the contact angle, the greater the hydrophobic surface property [13]. It was found that during the oxidation of coal the contact angle can change from $59^{\circ}$ (with un-oxidised surface) to $7^{\circ}$ (with fully oxidised surface) [13]. The higher the oxidation, the higher degree of particle hydrophilicity (less hydrophobic), making coal particles more difficult to float [9].

Many coal processing facilities face the challenge in oxidized coal flotation. Coal is oxidized by being exposed to oxygen with even a small amount during its mining, stockpiling and processing [14]. According to Korte (2001) [13], the main properties of coal changed by oxidation are: heat value, moisture and volatile matter content, size consistency, surface chemistry, and coking properties.

The extent of these property changes with the coal rank. The coal structure contains natural cracks, which are enlarged when oxidized. It was demonstrated that low rank coals developed extensive cracks, while higher rank coals were not physically affected by oxidation. This is due to more oxygen being 
exposed to the interior of the coal particles, especially for low rank coal, suggesting that it is best to reduce the particle size as late into the process as possible [14].

There are three stages of coal oxidation. The first stage is the formation of coal-oxygen functional groups on the coal surface with acidic properties. In the second stage, the organic components of the coal are transformed into hydroxyl carboxylic acids or humic acids. In the third stage, the humic acids are degraded into water soluble acids $[9,15]$. These functional groups form on the coal surface and reduce its natural hydrophobicity.

The low rank coals and/or oxidized coals contain larger amounts of the acidic functional groups. They reduce the surface charge (zeta potential) of the coal particles. Figure 1 shows the relationship between contact angle and zeta potential of coal particles as a function of oxidisation time. As coal is more oxidised, the contact angle decreases and zeta potential becomes more negative [16]. Such change makes it more difficult to separate from associated hydrophilic gangue minerals due to smaller difference in the degree of hydrophobicity.

Oxidized and low rank coal deposits are not highly demanded due to their poor recovery with generic coal flotation processes. If the oxidized coal only accounts for a small amount of the ore reserve, then it is generally processed and treated the same as fresh coal since its existence does not affect significantly the overall recovery. This is why there has been not an enough driving force to use alternative reagents for the industrial flotation of oxidized coal. Due to the depletion of high rank coal, industry now need to beneficiate also low rank and oxidized coal. There have been many studies on the flotation of oxidised coal; however, many studies do not offer unbiased comparisons of different frother reagents with MIBC [e.g. 7,16$]$.

Table 1. Flotation of coals in different ranks with the use of different reagents (reproduced and modified from [7]).

\begin{tabular}{|c|c|c|c|c|c|}
\hline \multirow{2}{*}{ Coal type } & \multirow{2}{*}{ Flotation reagents } & \multicolumn{2}{|c|}{ Concentrate } & \multicolumn{2}{|c|}{ Tailings } \\
\hline & & Yield $(\%)$ & $\operatorname{Ash}(\%)$ & Yield $(\%)$ & $\operatorname{Ash}(\%)$ \\
\hline $\begin{array}{l}\text { Bituminous medium- } \\
\text { volatile carbon }\end{array}$ & Tar oil $\left(\mathrm{C}_{14} \mathrm{H}_{18} \mathrm{O}_{4} \mathrm{ClN}_{5}\right) 2.5 \mathrm{~kg} / \mathrm{t}$ & 71.7 & 4.5 & 28.3 & 63.9 \\
\hline $\begin{array}{l}\text { Bituminous high-volatile } \\
\text { carbon }\end{array}$ & Tar oil $2.5 \mathrm{~kg} / \mathrm{t}$ & 38.9 & 3.9 & 61.1 & 23.2 \\
\hline $\begin{array}{l}\text { Bituminous high-volatile } \\
\text { carbon }\end{array}$ & $\begin{array}{l}\text { Kerosene }\left(\mathrm{C}_{12} \mathrm{H}_{26}-\mathrm{C}_{15} \mathrm{H}_{32}\right) 2.0 \mathrm{~kg} / \mathrm{t} \text { and } \\
\text { Nonyl alcohol }\left(\mathrm{C}_{9} \mathrm{H}_{20}\right) 0.62 \mathrm{~kg} / \mathrm{t}\end{array}$ & 79.1 & 4.1 & 20.9 & 62.1 \\
\hline
\end{tabular}

Different reagents are required to float oxidized and fresh coal due to the difference in their surface chemistries. Table 1 shows that reagents that float the higher ranked coals are not effective to float low rank or oxidized coals. Tar oil was used to float both high rank (i.e. bituminous medium-volatile carbon) and low rank (i.e. bituminous high-volatile carbon) coals and it gave a greater recovery for the naturally floating high rank coal while not improving the low rank coal recovery. This table shows the importance of selecting the correct reagents for low rank/ oxidized coal flotation because when using an oil collector (kerosene) with an alcohol frother (nonyl alcohol) the recovery (79\%) was even better than the higher rank coal recovery with tar oil $(72 \%)$. This can be explained by the frother properties of the nonyl alcohol helping emulsify the collector [7].

Table 2 shows the results of using MIBC as a frother on a variety of coals. The flotation of naturally hydrophobic coals (B and $\mathrm{C}$ ) was found to be slightly improved by the higher MIBC dosage and longer flotation time. For coal B recovery, as an example, $88 \%$ recovery with $5 \mathrm{mg}$ MIBC after 1 min flotation while $99 \%$ with $10 \mathrm{mg}$ MIBC after 2 min flotation. The low rank and oxidized coals A, H and I did not show noticeable responses to the MIBC while $\mathrm{E}$ and $\mathrm{G}$ responded; but not significant. MIBC is effective for improving flotation of medium volatile coals but the improvement decreases as the natural floatability of the coal particles is decreased. In the reported tests, MIBC was found to be not effective as pine oil and DowFroth 1012. This is due to short chain aliphatic alcohols only exhibiting frothing properties [7]. 
Table 2. Coal flotation recoveries in batch tests with MIBC as a frother (reproduced from [7]).

\begin{tabular}{cccc}
\hline \multirow{2}{*}{ coal } & \multicolumn{3}{c}{ Recovery (\%) } \\
\cline { 2 - 4 } & 5 mg frother & 5 mg frother & 10 mg frother \\
& 1 min flotation & 2 min flotation & 2 min flotation \\
\hline A & 5 & 8 & 24 \\
B & 88 & 94 & 99 \\
C & 85 & 93 & 97 \\
E & 13 & 26 & 57 \\
G & 3 & 7 & 10 \\
H & 3 & 5 & 5 \\
I & - & 2 & 9 \\
\hline
\end{tabular}

Regarding the effect of an activator ferrous sulphate on oxidized coal flotation, Wen and Sun (1981) [16] reported that at $\mathrm{pH} 6.5$ a greater coal recovery was given using pine oil as a frother compared to MIBC, as shown in Fig. 2. The results also showed that at this $\mathrm{pH}$ when pine oil was used as a frother with an amine collector the recovery was very similar to that of the pine oil by itself. This shows that pine oil is a frother with both frothing and collecting properties.

For oxidized coal flotation, pine oil is shown to give the better recovery from a selection of common frother reagents among MIBC, pine oil and a polyglycol synthetic frother [17]. The differences in recoveries between MIBC and pine oil can be explained in terms of the frother functions. MIBC functions as a water-miscible frother mainly by decreasing surface tension and has no collecting properties. Pine oil helps to coat the particles improving particle hydrophobicity allowing a better flotation recovery [18]. These tests show that pine oil alone performs better than MIBC alone; however, there is no comparison of pine oil and MIBC both in the presence of a collector. This highlights the need to test both reagents under the same conditions as it has been shown that MIBC has no collector properties (Fig. 2). This is due to the study reported by Wen and Sun (1981) [16] focusing on the effect of $\mathrm{pH}$ during oxidized coal flotation and not optimising coal recoveries using reagents. The results from the previous test work show that pine oil is a promising reagent for oxidized coal flotation. Its flash point is twice that of MIBC; although there were also promising studies using the newer synthetic polyglycol frothers (DowFroth) with flash points double that of pine oil. This would make them the preferred frother type in terms of OH\&S, as well as the potential for improving recoveries in oxidized coals. This suggests the need of comparison study covering a wider range of frothers, which was performed in this work, summarized in the following section.

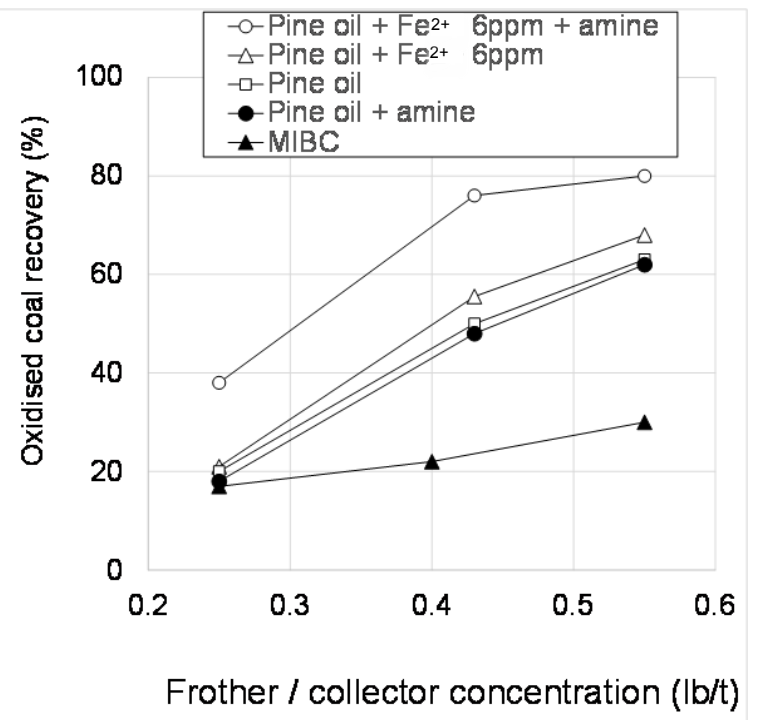

Figure 2. Effect of frother, amine and ferrous ions on the flotation recovery of oxidized coal at pH 6.5 (reproduced from $[16])$. 


\section{Frother Reagent Safety}

A number of different hazardous reagents are used in mining industry. Reagents can be toxic, flammable, carcinogenic or pose risks to the environment. Due to the varieties of hazards associated with different reagents, it can be hard to compare them in all the aspects of OH\&S. This report thus focuses on identifying alternative frothers replacing a frother MIBC which poses the low flash point in oxidized coal flotation. As such, the flash point was weighted as the $1^{\text {st }}$ criterion in the comparison of coal flotation frothers.

Flashpoint, exposure and environmental risk (and their potential risk ratings) of coal flotation frothers were summarized in Table 3 whose information was based on their SDS. The risk rating is scaled from one being the lowest risk, three being the medium risk and five being the highest risk for each of the properties compared. Among all the frothers, selected key frothers will be further discussed in the section 4.1 .

Table 3. Safety risk ratings on coal flotation frothers [1,19-25].

\begin{tabular}{|c|c|c|c|c|c|c|c|}
\hline Reagent & $\begin{array}{l}\text { Flash } \\
\text { point } \\
\left({ }^{\circ} \mathrm{C}\right) \\
\end{array}$ & $\begin{array}{l}\text { Risk } \\
\text { rating }\end{array}$ & $\begin{array}{l}\text { Exposure } \\
\text { risk }\end{array}$ & $\begin{array}{l}\text { Risk } \\
\text { Rating }\end{array}$ & Environmental risk & $\begin{array}{l}\text { Risk } \\
\text { Rating }\end{array}$ & $\begin{array}{l}\text { Total } \\
\text { Risk } \\
\text { Rating }\end{array}$ \\
\hline \multicolumn{8}{|l|}{ Mix } \\
\hline Flottec 132 Frother & 23 & 5 & $\begin{array}{l}\text { Odour, } \\
\text { Irritant }\end{array}$ & 3 & Minimal & 2 & 10 \\
\hline \multicolumn{8}{|l|}{ Aliphatic alchohols } \\
\hline $\operatorname{MIBC}\left(\mathrm{C}_{6} \mathrm{H}_{14} \mathrm{O}\right)$ & 39 & 5 & $\begin{array}{l}\text { Odour, } \\
\text { Irritant }\end{array}$ & 3 & Minimal & 2 & 10 \\
\hline \multicolumn{8}{|l|}{ Cyclic alchohols } \\
\hline $\begin{array}{l}\text { Pine Oil ( } \alpha \text {-terpinenol; active } \\
\left.\text { component of pine oil; } \mathrm{C}_{10} \mathrm{H}_{18} \mathrm{O}\right) \text { ) } \\
\text { Aromatic alchohols }\end{array}$ & 78 & 3 & Irritant & 2 & Minimal & 2 & 7 \\
\hline $\begin{array}{l}\text { Cresylic acid } \\
\left(\text { Cresol+xylenols; } \mathrm{CH}_{3} \mathrm{C}_{6} \mathrm{H}_{4} \mathrm{OH}\right) \\
\text { Alkoxy-type }\end{array}$ & 81 & 3 & Irritant & 2 & $\begin{array}{l}\text { Harmful to aquatic } \\
\text { organisms }\end{array}$ & 4 & 9 \\
\hline $\begin{array}{l}\text { 1,1,3-triethoxy butane (TEB; } \\
\left.\mathrm{C}_{10} \mathrm{H}_{22} \mathrm{O}_{3}\right)\end{array}$ & 80 & 3 & Irritant & 2 & $\begin{array}{l}\text { Not hazardous } \\
\text { according to Directive } \\
67 / 548 / \text { EEC }\end{array}$ & 2 & 7 \\
\hline \multicolumn{8}{|l|}{ Polyglycol-type } \\
\hline DowFroth $250\left(\mathrm{CH}_{3}\left(\mathrm{C}_{3} \mathrm{H}_{6} \mathrm{O}\right)_{4} \mathrm{OH}\right)$ & 149 & 2 & $\begin{array}{l}\text { Minor } \\
\text { irritant }\end{array}$ & 2 & Minimal & 2 & 6 \\
\hline DowFroth $1012\left(\mathrm{CH}_{3}\left(\mathrm{C}_{3} \mathrm{H}_{6} \mathrm{O}\right)_{6.3} \mathrm{OH}\right)^{*}$ & 172 & 1 & Minimal & 1 & Minimal & 3 & 5 \\
\hline 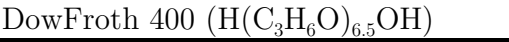 & 195 & 1 & Minimal & 1 & Minimal & 2 & 4 \\
\hline
\end{tabular}

$*[26]$

\subsection{Key Rating Components}

The flash points of the coal flotation frothers listed in Table 3 vary from $23^{\circ} \mathrm{C}$ to $195^{\circ} \mathrm{C}$. There are other frothers that may have a higher flash point but they will not be considered in this report. The alcohol based frothers (e.g. MIBC) exhibit the highest risk rating for the F.P. while the polyglycol ether frothers (e.g. DowFroth) have the lowest risk, making the latter more desirable as a frother reagent.

To rank the reagent exposure risks, the effects of the frother on skin and eyes through inhalation and ingestion were compared in the risk rating matrix based on the information in the chemical SDS. Most chemicals incur a risk of slight skin irritation, eye irritation or internal issues as a result of inhalation or ingestion. The likelihood of exposure can be easily minimized by the use of engineering controls and personal protective equipment (PPE), although some of the frother exposure reactions were listed as 
more severe than the others and these were ranked higher. MIBC and Flottec 132 Frother were ranked as medium risks due to the vapors produced being a respiratory irritant and having strong odours.

None of the frothers poses any significant threats to the environment if it is used and disposed correctly. The higher rankings come from the degree of biodegradability; DowFroth 1012 does not readily biodegrade in the presence of oxygen; however, it is relatively non-toxic to the environment.

As conclusions of the risk rating table of the coal frother options, DIBK and Flottec 132 frother are of similar risk ratings as MIBC and thus will not be considered as replacements for MIBC. They will not be reviewed in the following analysis of frother properties in oxidized coal flotation. The main focus will be on the comparison of MIBC with pine oil and the DowFroth reagents based on their total risk rating (Table 3) and usage in industry. They will be compared in the following section 4.2.

\subsection{Comparison of Key Frothers}

MIBC is the most common frother in the mining industry as it is versatile and inexpensive. It is an alcohol type frother derived from oil refining. It is generally preferred over other frothers as its froth carry more water and provide better drainage of mechanically entrained particles. One disadvantage of using MIBC is the lack of stability; therefore, stepwise addition is needed to maintain froth in flotation cells. It forms uncompact froth with large size bubbles, suggesting some of the other frothers can be more suitable to float oxidized coal [28]. In the use of MIBC, the largest issue is the OH\&S concerns as MIBC has a low flash point and high vaporisation rate.

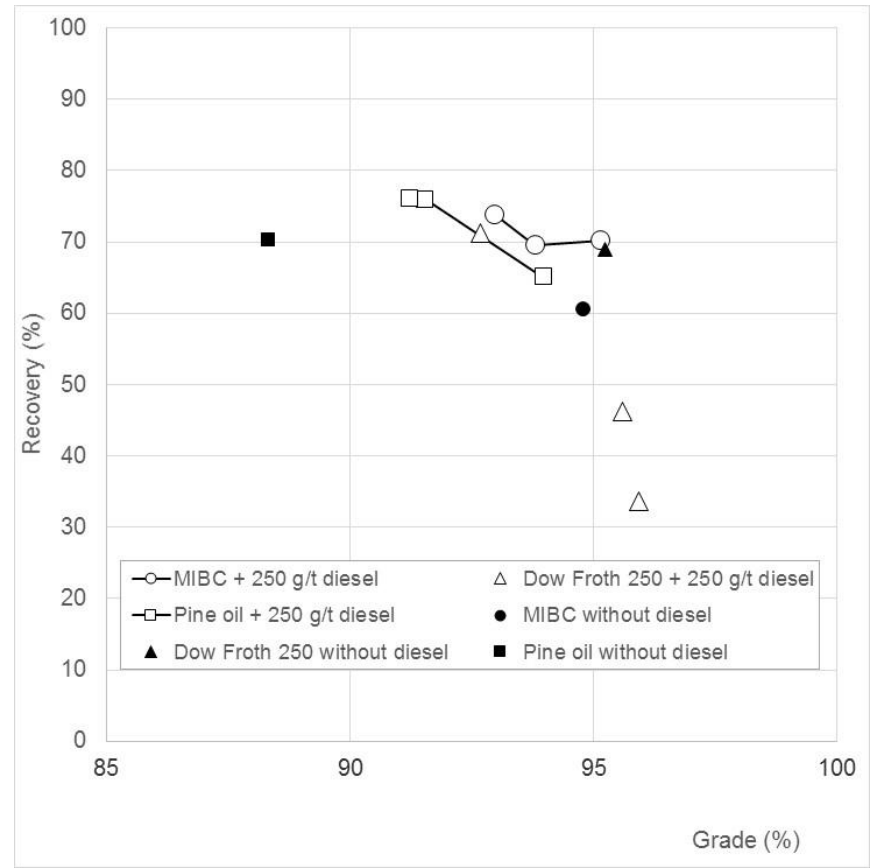

Figure 3. Grade - recovery curve of coal flotation tests with 3 different frothers in the absence or presence of 250 $\mathrm{g} / \mathrm{t}$ diesel collector (adapted from [27]).

Dow Chemicals developed a series of frothers which are completely water soluble and are produced from synthetic brake fluid. The molecular weight and carbon chain length determine the power and performance of the frother. The higher the molecular weight, the less selective but the stronger the frother is [6]. The flash point of DowFroth 250 is $149{ }^{\circ} \mathrm{C}$. The froth produced is rigid, compact and lasts for a long time. The polyglycol ethers also have collecting properties and can be used standalone without a collector addition as well as having smaller addition rates than MIBC and pine oil [28]. DowFroth 250 is the most common number used among DowFroth series as it is found to give good recoveries over a variety of minerals.

Pine oil has been used since the early days of froth flotation, and at one stage it was the dominant natural oil frother due to its availability. However since synthetic frothers have been developed, there 
has been a downturn in the use of pine oil. This is due to the inconsistencies associated with using a natural product. The composition is not always constant; thus the frothing properties can vary and it is difficult to get similar grade and frother performance from different supply companies. It is derived from the distillation of pine trees or as a by-product from oil refineries. The alcohol content of commercial agents varies from 60 to 90 per cent. The flash point varies from 75 to 85 degrees depending on the alcohol content. Pine oil can often be used without a collector due to its collecting properties. This could be used to reduce the number of hazardous chemicals stored on sites. Pine oil produces stable close knit bubbles that minimise unnecessary particle fallout; however the concentrate grade can suffer due to gangue minerals being trapped in the froth [28]. Pine oil is effective to aim a high recovery but a lower grade due to the small, tight bubbles produced in the froth which increases gangue entrapment [6].

Otsuki and Miller (2018) [27] reported the experimental investigation of the comparison of the above 3 frothers on coal flotation performance. Figure 3 shows the summary of their results indicating that the coal grade and recovery relationship from the flotation tests with the 3 different frothers. Pine oil had the highest recovery $(76 \%)$ with the high grade (91-92\%), similar to the two other frothers $(93-96 \%)$. From this graph, it can be seen that pine oil was the effective frother achieving similar results with MIBC. This satisfies the purpose of this project to find a frother with a greater flash point than MIBC that performs better than or equal to MIBC making the processing site safer for employees. Dow Froth 250 obtained the higher grade with lower recovery than the others. It can be used in the cleaning stage if appropriate.

\section{Conclusions and Recommendations}

The OHS culture on mine sites is constantly changing and mining companies need to keep up with the changes and avoid risk incidents and injuries. The coal processing industry is no exception; potentially hazardous reagents are currently used in coal flotation. The aliphatic alcohol frother MIBC is used to improve the coal flotation performance. MIBC has a low flash point. It has caused many incidents including a fire at a coal processing facility in Queensland. Such potential MIBC issue has justified this literature review focusing the OHS associated with the use of reagents in oxidized coal flotation.

The purpose of this review was to investigate coal frothers that are safer than MIBC but can also simultaneously provide equal or better flotation results for continued performance. A series of frothers in different categories were compared and ranked in safety and environmental point of views, as well as coal flotation performance. From the reagent safety analysis and previous work, it was found that pine oil and DowFroth 250 have a higher flash point and are safer options. They were further compared with MIBC to provide a deeper insight for the selection of safer and greener frother option.

After completing a literature review for the safer flotation of oxidized coal it was confirmed that:

- Pine oil has dual frothing and collecting properties. This is shown in the performance of tests using no collector where the results were equal to or better than the results when adding the collector. Pine oil has the potential to be used as a stand-alone reagent for coal flotation that would remove the need for a potentially hazardous collector making it safer on site.

- DowFroth 250 has also possesses the dual frothing and collecting properties, and has a high flash point double of MIBC making it the safer than MIBC.

- The above suggestions were also supported by experimental investigation by Otsuki and Miller (2018) [27].

\section{References}

1. DOW CHEMICAL (AUSTRALIA) 2013. Methyl Isobutyl Carbinol. Material Safety Data Sheet. 8th January 2013 ed.

2. Garland, P. 2003. Fire at an MIBC Pump. Safety Alert. Queensland: Queensland Government.

3. WORLD COAL ASSOCIATION. 2012. Coal Statistics [Online]. Available: http://www.worldcoal.org/resources/coal-statistics/ [Accessed 4th April 2013].

4. Aaron, N., Luttrell, G.H. 2015. A review of state-of-the- art processing operations in coal preparation. Int. J. Min. Sci. Tech., 25, 511-521. 
5. Kracht, W., Hunt, C., 2016. Indirect measurement of frother concentration based on l-CCC curves. Minerals Engineering, 92, 110-113.

6. Sam, H.K.A.A. 2011. Flotation Frothers: Review of Their Classifications, Properties and Preparation. The Open Mineral Processing Journal, 25-44.

7. Laskowski, J. 2001. Coal Flotation and Fine Coal Utilization. Burlington: Elsevier Science.

8. Chander, S.H.P.A.B.M. 1993. Flotation and Wettability of a Low Rank Coal in the Presence of Surfactants. Minerals and Metallurgical Processing, February 94, 7.

9. Dey, S. 2012. Enhancement in hydrophobicity of low rank coal by surfactants - A critical overview. Fuel Processing Technology, 94, 151-158.

10. Laskowski, J., Woodburn, J. 1998. Frothing in Flotation 2, England, Gordon and Breach Science Publishers.

11. Cho, Y.S. 2001. Effect of Flotation Frothers on Bubble Size and Foam Stability. Master of Applied Science, The University of British Columbia.

12. Agheli, S., Hassanzadeh, A., Vaziri, B., Hassas, Hasanzadeh, M. 2018. Effect of pyrite content of feed and configuration of locked particles on rougher flotation of copper in low and high pyritic ore types. International Journal of Mining Science and Technology, 28, 167-176.

13. Korte, G. J. D. 2001. Beneficiation of Weathered Coal. Republic of South Africa: CoalTech 2020.

14. Polat, M., Polat, H., Chander, S. 2003. Physical and chemical interactions in coal flotation. International Journal of Mineral Processing, 72, 199-213.

15. Sarikaya, M., Özbayoglu, G. 1995. Flotation characteristics of oxidized coal. Fuel, 74, 291-294.

16. Wen, W.W., Sun, S.C. 1981. An Electrokinetic Study on the Oil Flotation of Oxidized Coal. Separation Science and Technology, 16, 1491-1521.

17. Bhattacharya, S.S.D.A.M.Z.A. Frother Dependency in Coal Flotation. India: Indian School of Mines.

18. Gayle, J.B., Shotts, R.Q. 1985. Laboratory Investigation of the Effect of Oxidation on Coal Flotation. Report of Investigations. California: California Institute of Technology.

19. DOW CHEMICAL (AUSTRALIA) 2011a. Dowfroth 250. Material Safety Data Sheet.

20. DOW CHEMICAL (AUSTRALIA) 2011b. Dowfroth 400. Material Safety Data Sheet.

21. DOW CHEMICAL (AUSTRALIA) 2011c. Dowfroth 1012. Material Safety Data Sheet.

22. FLOTTEC 2012. Flottec F132 Frother. Material Safety Data Sheet.

23. SPECTRUM 2008. Pine Oil. Material Safety Data Sheet.

24. TCI America 2006. Cresylic acid. Material Safety Data Sheet.

25. Chemsrc. 1,1,3-triethoxybutane. Material Safety Data Sheet. https://www.chemsrc.com/en/cas/5870-82-6_761834.html. Accessed on 21/9/2018.

26. Gupta, C.K. Extractive Metallurgy of Molybdenum, CRC Press, Boca Raton, 2000, pp.100-101.

27. Otsuki, A., Miller, T. 2018. Experimental investigation on safer frother option for coal flotation, Current Works in Mineral Processing, 1, 1-12.

28. Meech, J. A. 2006. Froth Flotation. University of British Columbia. 